CLINICAL STUDY

\title{
Pharmacokinetics and pharmacodynamics of GH: dependence on route and dosage of administration
}

\author{
Alexandra Keller, Zida $\mathrm{Wu}^{1}$, Juergen Kratzsch ${ }^{2}$, Eberhard Keller, Werner F Blum ${ }^{3}$, Astrid Kniess ${ }^{4}$, Rainer Preiss ${ }^{5}$, \\ Jens Teichert ${ }^{5}$, Christian J Strasburger ${ }^{1}$ and Martin Bidlingmaier ${ }^{6}$ \\ Hospital for Children and Adolescents, University of Leipzig, Oststr. 21-25, D-04317 Leipzig, Germany, ${ }^{1}$ Division of Clinical Endocrinology, Department of \\ Medicine, Charité University-Medicine, 10117 Berlin, Germany, ${ }^{2}$ Institute of Laboratory Medicine, Clinical Chemistry and Molecular Diagnostics, \\ University of Leipzig, 61350 Leipzig, Germany, ${ }^{3}$ Eli Lilly \& Co., Bad Homburg, Germany and Children's Hospital, University of Giessen, 01731 Giessen, \\ Germany, ${ }^{4}$ Institute of Doping Analysis and Sports Biochemistry, 04107 Kreischa, Germany, ${ }^{5}$ Institute of Clinical Pharmacology, University of Leipzig, \\ Leipzig, Germany and ${ }^{6}$ Department of Internal Medicine, Ludwig Maximillian University of Munich, 80336 Munich, Germany \\ (Correspondence should be addressed to A Keller; Email: alexandra.keller@medizin.uni-leipzig.de)
}

\begin{abstract}
Objective: Pharmacokinetic and pharmacodynamic data after recombinant human GH (rhGH) administration in adults are scarce, but necessary to optimize replacement therapy and to detect doping. We examined pharmacokinetics, pharmacodynamics, and $20 \mathrm{kDa} G H$ after injection of rhGH at different doses and routes of administration.

Design: Open-label crossover study with single boluses of rhGH.

Methods: Healthy trained subjects (10 males, 10 females) received bolus injections of rhGH on three occasions: $0.033 \mathrm{mg} / \mathrm{kg}$ s.c., $0.083 \mathrm{mg} / \mathrm{kg}$ s.c., and $0.033 \mathrm{mg} / \mathrm{kg}$ i.m. Concentrations of 22 and $20 \mathrm{kDa}$ GH, IGF-I, and IGF-binding proteins (IGFBP)-3 were measured repeatedly before and up to $36 \mathrm{~h}$ after injection.

Results: Serum GH maximal concentration $\left(C_{\max }\right)$ and area under the time-concentration curve (AUC) were higher after i.m. than s.c. administration of $0.033 \mathrm{mg} / \mathrm{kg}\left(C_{\max } 35.5\right.$ and $12.0 \mu \mathrm{g} / \mathrm{l}$; AUC 196.2 and 123.8). $C_{\max }$ and AUC were higher in males than in females $(P<0.01)$ and pharmacodynamic changes were more pronounced. IGFBP-3 concentrations showed no dose dependency. In response to rhGH administration, $20 \mathrm{kDa}$ GH decreased in females and remained suppressed for 14-18 h (low dose) and $30 \mathrm{~h}$ (high dose). In males, $20 \mathrm{kDa}$ GH was undetectable at baseline and throughout the study.

Conclusions: After rhGH administration, pharmacokinetic parameters are mainly influenced by route of administration, whereas pharmacodynamic variables and $20 \mathrm{kDa} \mathrm{GH}$ concentrations are determined mainly by gender. These differences need to be considered for therapeutic use and for detection of rhGH doping.
\end{abstract}

European Journal of Endocrinology 156 647-653

\section{Introduction}

In growth hormone (GH)-deficient adult patients, subcutaneous (s.c.) administration of recombinant human GH (rhGH) at a fixed dose results in less pronounced effects in females than in males (1-3). This is thought to be at least partly due to modulation of hepatic insulin-like growth factor-I (IGF-I) generation by endogenous and exogenous estrogens $(4,5)$. In addition, male and female patterns of fat distribution differ substantially and could potentially be associated with differences in absorption from the injection depot of $\mathrm{rhGH}(6,7)$. The administration route in early studies of rhGH was by intramuscular (i.m.) injection; sex differences were not noted but these studies were in children who would not have developed adult differences between the sexes. The route was changed to the current standard of s.c. injection due to patient preference, but there were differences in absorption characteristics noted between the two routes of administration $(8,9)$. While pharmacokinetic data have been reported from early studies in children (8, 10 ), literature reports of pharmacokinetics in adults are scarce (11).

Unfortunately, rhGH has been misused, particularly in sport, and the methods to uncover such misuse have limitations $(12,13)$. Exogenously administered rhGH is structurally identical to endogenous $22 \mathrm{kDa} \mathrm{GH}$, which is the isoform predominantly secreted in humans $(14$, 15). The most commonly used GH immunoassays recognize equally the $22 \mathrm{kDa}$ isoform and the $20 \mathrm{kDa}$ $\mathrm{GH}$, which results from alternative splicing. It was 
suggested that development of immunoassays that could differentiate between the isoforms could be used to assess misuse of rhGH (15).

The current study was designed to investigate the pharmacokinetics and pharmacodynamics of rhGH in recreationally trained adults after single dose injections via s.c. and i.m. routes and to assess differences between males and females. Pharmacokinetics of the $22 \mathrm{kDa}$ isoform were determined and pharmacodynamics were assessed from changes in the serum concentrations of the $20 \mathrm{kDa}$ isoform, IGF-I, and IGF-binding proteins (IGFBP)-3.

\section{Subjects and methods}

\section{Subjects}

Ten males and ten females were selected from a cohort of 50 healthy young adults based on the level of sport activities. Inclusion criteria were: aged 18-35 years, body mass index (BMI) $19-27 \mathrm{~kg} / \mathrm{m}^{2}$, regular physical exercise at least three times per week and, in females, continuous use of oral contraceptives. Subjects were excluded if they had any chronic illness, took any medications known to interfere with endocrine function or reported any previous use of rhGH. Before entering the study, a full physical examination was performed and blood was taken for routine biochemistry, hematology, fasting blood glucose, and liver enzymes. The local ethics committee of the University of Leipzig, Germany, approved the protocol. All subjects gave written informed consent and the study was conducted in accordance with the principles of the Declaration of Helsinki and the guidelines of good clinical practice.

\section{Study design}

The study used a randomized crossover design. Subjects were admitted to our clinical research unit for the three study periods, each starting at $0600 \mathrm{~h}$ after an overnight fast. Intravenous catheters were inserted in an antecubital vein and blood samples were drawn at 60 and 0 min (baseline) before rhGH administration then at 2-h intervals for the following 36 h. At $0 \mathrm{~h}$, rhGH (Humatrope, Eli Lilly) was administered as a bolus of either $0.033 \mathrm{mg} / \mathrm{kg}$ body weight s.c., $0.083 \mathrm{mg} / \mathrm{kg}$ s.c. or $0.033 \mathrm{mg} / \mathrm{kg}$ i.m., according to a previously defined randomization scheme. Over the three study periods, each patient received each of the three rhGH doses in randomized order; patients were blinded regarding the low and high s.c. doses. Study periods were separated by a washout of 4 weeks to synchronize with the menstrual cycle in females.

\section{Hormone measurements}

Serum GH concentration was assayed by two sandwich immunoassays. Assay 1 (mAb 3B4/biotinylated mAb 10A7) utilized a capture antibody, which preferentially recognizes the monomeric $22 \mathrm{kDa}$ isoform of $\mathrm{GH}$, which is identical to rhGH and the lower detection limit was $0.1 \mu \mathrm{g} / \mathrm{l}(12)$. Intraassay coefficients of variation were 6.5 and $4.8 \%$ at concentrations of 0.8 and $6.2 \mu \mathrm{g} / \mathrm{l}$ respectively. Interassay coefficients of variation at the same concentrations were 8.2 and $6.1 \%$ respectively (12). Assay 2 was used for measuring the $20 \mathrm{kDa} \mathrm{GH}$ isoform using two monoclonal antibodies with no cross-reactivity to $22 \mathrm{kDa} \mathrm{GH}$; intra- and interassay coefficients of variation were 5.4 and $7.5 \%$ at $1 \mu \mathrm{g} / \mathrm{l}$ and the limit of quantification was $0.05 \mu \mathrm{g} / \mathrm{l}(13)$. Assay 1 is referred to as ' $22 \mathrm{kDa}$ GH' while assay 2 is referred to as ' $20 \mathrm{kDa}$ GH'.

Serum IGF-I was measured by an automated chemiluminescence immunoassay (Nichols Advantage IGF-I, Nichols Institute Diagnostics, San Juan Capistrano, CA, USA) using acidification and IGF-II excess to eliminate interference from IGFBP. Serum IGFBP-3 was analyzed by a RIA described previously (16). All serum samples were stored at $-20{ }^{\circ} \mathrm{C}$ until analysis.

\section{Calculation of pharmacokinetic and pharma- codynamic parameters}

Pharmacokinetic parameters were estimated using standard noncompartmental analyses with the WinNonlin pharamacokinetic software version 4.01 (Pharsight Corp., Mountain View, CA, USA).

Area under the time-concentration curve $\left(\mathrm{AUC}_{\text {last }}\right)$ was defined as the area under the curve from the time of dosing to the last measurable concentration, calculated using the linear trapezoidal rule. $\mathrm{AUC}_{\text {inf }}$ was calculated by extrapolation to infinity using the terminal half-life $\left(t_{1 / 2 \mathrm{z}}\right)$ estimated with log-linear regression $(\mathrm{AUC}=$ $\left.\mathrm{AUC}_{\text {last }}+\mathrm{AUC}_{\text {inf }}\right)$. Mean residence time (MRT) was estimated as the area under the first moment curve (AUMC) divided by AUC. Apparent plasma clearance (CL/F) was defined as the ratio of dose injected and AUC, and apparent volume of distribution $\left(V_{\mathrm{z}} / \mathrm{F}\right)$ was calculated as $(\mathrm{CL} / \mathrm{F}) / \lambda_{\mathrm{z}}(17)$.

Instead of total AUC, the increase of IGF-I or IGFBP-3 above baseline levels was used for calculating the parameter $\triangle \mathrm{AUC}$ 0-36.

\section{Statistical methods}

Data are given as mean \pm s.D. or as median and interquartile range $(\mathrm{Q} 1, \mathrm{Q} 3)$. The $\mathrm{GH}$ concentrations below the detection limit of the assays were assigned to $0 \mu \mathrm{g} / \mathrm{l}$. Comparisons between sexes, dosages, and routes of administration were performed with the Wilcoxon test or the non-paired U-Mann-Whitney test as 
indicated. Spearman rank correlation with two-tailed probability values was used to test the association between the variables. Statistical significance was assumed for $P<0.05$. All statistical calculations were performed with Excel version 8.0 and SPSS version 11.0 for Windows (SPSS Inc., Chicago, IL, USA).

\section{Results}

\section{Baseline characteristics}

Baseline characteristics of the study subjects are shown in Table 1. Both 22 and $20 \mathrm{kDa}$ GH at baseline were significantly higher in females than in males. In contrast, baseline serum IGF-I levels were significantly lower in females than in males. Differences between females studied in the follicular phase and in the luteal phase were not significant (data not shown).

\section{Pharmacokinetics}

Figure 1A depicts serum concentration profiles of $22 \mathrm{kDa} \mathrm{GH}$ over time in males and females by rhGH dose and route of administration. The pharmacokinetic parameters (Table 2) were not correlated with age or $\mathrm{BMI}$ at any dose or route of administration.

When the same $\mathrm{rhGH}$ dose $(0.033 \mathrm{mg} / \mathrm{kg})$ was administered, a significantly higher $22 \mathrm{kDa} \mathrm{GH}$ peak maximal concentration $\left(C_{\max }\right)$ and AUC were observed with the i.m. compared with s.c. route in males but not females. There was no difference between males and females for $C_{\max }$ and $\mathrm{AUC}$ with s.c. rhGH, irrespective of the dose. In contrast, after i.m. administration mean $C_{\max }$ and $\mathrm{AUC}$ were significantly higher in males than females, with a concomitantly lower $\mathrm{CL} / \mathrm{F}$ in males. MRT was shorter in males than females in the low-dose group, irrespective of route of administration.

\section{Pharmacodynamics: IGF-I and IGFBP-3 responses}

Figure $1 \mathrm{~B}$ and $\mathrm{C}$ show the time course of serum IGF-I and IGFBP-3 concentrations in males and females by rhGH dose and route of administration. Subjects with higher baseline IGF-I concentrations showed a greater response to rhGH than those with a lower baseline concentration $(P<0.01)$; this association was observed at all three study periods.

The increase from baseline integrated over time ( $\triangle$ AUC 0-36) was higher with the high dose for both IGF-I and IGFBP-3. There were no significant differences for IGF-I or IGFBP-3 parameters between s.c. and i.m. routes with the same rhGH dose. $T_{\max }$ for serum IGF-I differed between males and females in the high-dose group. IGF-I $\triangle$ AUC 0-36 showed a clear sex difference at the low dose, with higher values in males compared with females; this was independent of the route of administration. At the high dose, the difference between the sexes was not significant. IGFBP-3 $\triangle$ AUC 0-36 was significantly higher in males than females at the low s.c. dose, while at the high s.c. dose similar values were observed (Table 3).

\section{Pharmacodynamics: 20 kDa GH}

At baseline, $20 \mathrm{kDa} \mathrm{GH}$ was detectable in all women in all three study periods; rapid suppression occurred after injection of rhGH (Fig. 2). In females, mean $20 \mathrm{kDa} \mathrm{GH}$ levels decreased from 0.4 at baseline to below $0.2 \mu \mathrm{g} / \mathrm{l}$ within $2 \mathrm{~h}$ after injection of rhGH. Duration of $20 \mathrm{kDa} \mathrm{GH}$ suppression in females was dose dependent; reoccurrence of $20 \mathrm{kDa}$ GH secretion was observed in the low-dose s.c. group after $26 \mathrm{~h}$, in the low-dose i.m. group after $28 \mathrm{~h}$, and in the high dose s.c. group after $34 \mathrm{~h}$. In contrast, in males $20 \mathrm{kDa} \mathrm{GH}$ levels were close to or below the lower limit of quantification $(0.05 \mu \mathrm{g} / \mathrm{l})$ of the assay at baseline and throughout the observation period.

Table 1 Baseline characteristics of the study subjects.

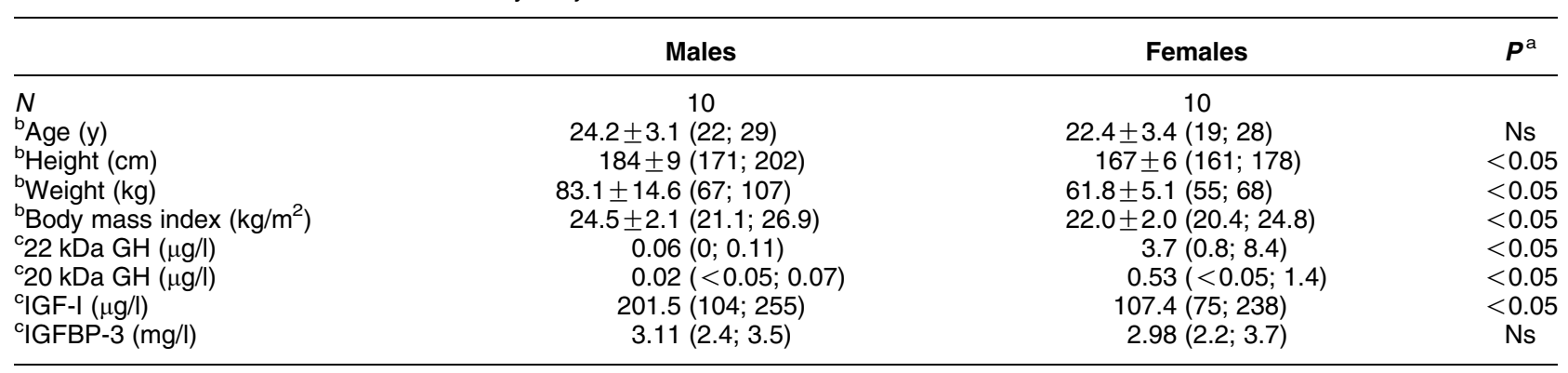

${ }^{a}$ Wilcoxon signed rank test.

${ }^{\mathrm{b}}$ Mean \pm s.D. (range)

'Median (Q1/Q3). 


\section{Interdependence of pharmacokinetics and pharmacodynamics}

The relationship between AUC for $22 \mathrm{kDa}$ GH and $\triangle \mathrm{AUC}$ 0-36 IGF-I was investigated by regression analysis. Combining all three study periods, the data sets $(n=30$ per sex) showed normal distribution (KolmogorovSmirnov test, $P<0.05)$, thus allowing application of a linear regression model. A significant $(P<0.05)$ correlation was found between bioavailable $\mathrm{GH}$ and induced increase in IGF-I in both sexes, particularly with the high dose. At low GH AUC values, males showed higher IGF-I $\triangle$ AUC 0-36 than females; this difference was not seen at higher GH AUC values.

\section{Adverse events}

The most frequent adverse event was diarrhea occurring within $24 \mathrm{~h}$ after rhGH in six subjects receiving high dose and two subjects receiving low-dose s.c. injections. In four of the six subjects from the high-dose group, diarrhea was accompanied by moderate dizziness. Symptoms spontaneously ceased by the end of the study period ( $36 \mathrm{~h}$ ). These episodes of diarrhea were not related to any identifiable causes such as dietary issues or gastrointestinal infections. Three subjects experienced enhanced sweating without obvious relation to the dose. One subject presented with decreased blood pressure, dizziness and vomiting $24 \mathrm{~h}$ after administration of the high dose; the symptoms resolved within $6 \mathrm{~h}$. No edema was observed, and neither arthralgia nor headache was reported.

\section{Discussion}

The present data demonstrate that gender, dose and route of administration specifically alter bioavailability of and response to exogenous rhGH in healthy young adults. Pharmacokinetic variables were mainly influenced by the route of administration, whereas pharmacodynamic responses were primarily determined by sex. Furthermore, suppression of the $20 \mathrm{kDa}$ GH isoform after injection of rhGH could be demonstrated only in women; $20 \mathrm{kDa}$ GH levels in males were already low at baseline.

We assessed trained, but not elite level, subjects and highly trained individuals may respond differently to rhGH administration. With no exogenous rhGH, reduced serum IGF-I and IGFBP-3 concentrations have been reported during intense training $(18,19)$. The dose of rhGH used in this study was supraphysiological, because it can be assumed that illegal use by athletes will be at high doses (20). Physiological rhGH replacement in GH-deficient adults requires approximately one-third to one-fifth of the dose used in this study (21). Despite the high rhGH doses, we observed few of the side effects 
Table 2 Pharmacokinetic data of $22 \mathrm{kDa}$ growth hormone $(\mathrm{GH})$ by sex. Values are given as median (range).

\begin{tabular}{|c|c|c|c|c|c|c|}
\hline & \multicolumn{3}{|c|}{ rhGH dose and route } & \multirow[b]{2}{*}{$\begin{array}{l}P \text { value of } \\
A \text { versus } B\end{array}$} & \multirow[b]{2}{*}{$\begin{array}{l}P \text { value of } \\
A \text { versus C }\end{array}$} & \multirow[b]{2}{*}{$\begin{array}{l}P \text { value of } \\
B \text { versus C }\end{array}$} \\
\hline & $\begin{array}{c}\text { Group A } \\
0.033 \mathrm{mg} / \mathrm{kg} \text { s.c. }\end{array}$ & $\begin{array}{c}\text { Group B } \\
0.033 \mathrm{mg} / \mathrm{kg} \mathrm{im}\end{array}$ & $\begin{array}{c}\text { Group C } \\
0.083 \mathrm{mg} / \mathrm{kg} \text { s.c. }\end{array}$ & & & \\
\hline \multicolumn{7}{|l|}{ AUC $\left(h^{*} \mu \mathrm{g} / \mathrm{l}\right)$} \\
\hline All & $123.8(68.1 / 435.2)$ & $196.2(110.4 / 476.1)$ & $407.9(206.7 / 546.8)$ & $P<0.05$ & $P<0.03$ & $P<0.05$ \\
\hline Males & $134.9(85.7 / 204.4)$ & $209.2^{*}(151.7 / 476.1)$ & $413.5(283.1 / 546.8)$ & $P<0.05$ & $P<0.03$ & $P<0.05$ \\
\hline Females & $123.8(68.1 / 435.2)$ & $145.5^{\star}(110.4 / 308.4)$ & $364.6(206.7 / 476.6)$ & Ns & $P<0.03$ & $P<0.53$ \\
\hline \multicolumn{7}{|c|}{ Maximal concentration $\left(C_{\max } ; \mu \mathrm{g} / \mathrm{l}\right)$} \\
\hline All & $12.0(5.5 / 32.7)$ & $35.5(14.3 / 85.7)$ & $39.9(19.9 / 74.2)$ & $P<0.03$ & $P<0.01$ & Ns \\
\hline Males & $15.5(7.3 / 32.7)$ & $41.8^{\dagger}(21.9 / 85.7)$ & $47.8(24.3 / 74.2)$ & $P<0.04$ & $P<0.01$ & Ns \\
\hline Females & $12.0(5.5 / 22.6)$ & $21.2^{\dagger}(14.3 / 54.2)$ & $35.6(19.9 / 72.1)$ & $P<0.03$ & $P<0.01$ & Ns \\
\hline \multicolumn{7}{|c|}{ Terminal half-life $\left(t_{1 / 2 z} ; \mathrm{min}\right)$} \\
\hline All & $116.3(31.6 / 262.1)$ & $113.8(72.0 / 235.8)$ & $148.4(101.0 / 234.7)$ & Ns & Ns & Ns \\
\hline Males & $130.4(82.0 / 259.9)$ & $106.3(72.0 / 193.6)$ & $144.8(101.1 / 204.9)$ & Ns & Ns & Ns \\
\hline Females & $112.4(31.6 / 262.1)$ & $123.1(76.9 / 235.8)$ & $169.2(115.5 / 234.7)$ & Ns & Ns & Ns \\
\hline \multicolumn{7}{|l|}{ MRT (h) } \\
\hline All & $9.8(4.4 / 15.2)$ & $6.0(4.0 / 13.2)$ & $8.3(5.7 / 10.7)$ & Ns & Ns & Ns \\
\hline Males & $7.5^{*}(4.4 / 10.5)$ & $5.3^{*}(4.0 / 7.1)$ & $7.5(5.7 / 9.8)$ & Ns & Ns & Ns \\
\hline Females & $10.9^{\star}(7.0 / 15.2)$ & $7.2^{*}(5.1 / 13.2)$ & $8.4(6.8 / 10.7)$ & Ns & Ns & Ns \\
\hline \multicolumn{7}{|c|}{$\mathrm{CL} / \mathrm{F}(\mathrm{ml} / \mathrm{h} / \mathrm{kg})$} \\
\hline All & $261.7(73.4 / 454.1)$ & $167.7(69.2 / 288.4)$ & $201.9(150.5 / 397.2)$ & $P<0.05$ & Ns & Ns \\
\hline Males & $258.8(161.1 / 381.7)$ & $156.3^{*}(69.2 / 216.8)$ & $197.0(150.5 / 290.9)$ & $P<0.05$ & Ns & Ns \\
\hline Females & $261.7(73.4 / 454.1)$ & $197.8^{*}(101.8 / 288.4)$ & $224.3(173.0 / 397.2)$ & Ns & Ns & Ns \\
\hline
\end{tabular}

${ }^{\star} P<0.05,{ }^{\dagger} P<0.01$ for difference between males and females calculated by the U-Mann-Whitney test; Ns, not significant. Wilcoxon Test was used for between-group comparisons.

previously described in adults with GH deficiency $(22,23)$. However, a high frequency of diarrhea was seen, particularly after administration of the high rhGH dose. We found no explanation in regard to diet or gastrointestinal infections, and speculate that fluid regulation disturbances induced by the high dose could have caused the diarrhea (24).
$C_{\max }$ and AUC were higher after i.m. than s.c. injection of the identical dose, in accordance with previous reports (25) indicating that serum GH after i.m. injection shows a higher amplitude and shorter duration compared with s.c. injection. Significant differences between males and females were found for $\mathrm{GH} C_{\max }$ and AUC after i.m., but not s.c. injection.

Table 3 Pharmacodynamics of insulin-like growth factor-I (IGF-I) and IGF-binding protein (IGFBP)-3 stratified by sex. Values are given as median (range).

\begin{tabular}{|c|c|c|c|c|c|c|}
\hline & \multicolumn{3}{|c|}{ rhGH dose and route } & \multirow{2}{*}{$\begin{array}{c}P \text { value of } A \\
\text { versus } B\end{array}$} & \multirow{2}{*}{$\begin{array}{c}P \text { value of } A \\
\text { versus } C\end{array}$} & \multirow{2}{*}{$\begin{array}{c}P \text { value of } B \\
\text { versus } C\end{array}$} \\
\hline & A: $0.033 \mathrm{mg} / \mathrm{kg}$ s.c. & B: 0.033 mg/kg i.m. & C: $0.083 \mathrm{mg} / \mathrm{kg}$ s.c. & & & \\
\hline \multicolumn{7}{|l|}{ IGF-I } \\
\hline \multicolumn{7}{|l|}{$T_{\max }(\mathrm{h})$} \\
\hline All & $15.0(6 / 30)$ & $14.0(8 / 28)$ & $24.0(14 / 24)$ & Ns & Ns & Ns \\
\hline Males & $21.0(6 / 30)$ & $19.0(12 / 28)$ & $28.0^{*}(18 / 36)$ & Ns & Ns & Ns \\
\hline Females & $14.0(6 / 22)$ & $13.0(8 / 18)$ & $17.0^{*}(14 / 28)$ & Ns & Ns & Ns \\
\hline \multicolumn{7}{|l|}{$C_{\max }(\mu \mathrm{g} / \mathrm{l})$} \\
\hline All & $302(89 / 550)$ & $303(194 / 567)$ & $413(238 / 725)$ & Ns & $<0.05$ & $<0.05$ \\
\hline Males & $362(267 / 550)$ & $338(238 / 567)$ & $441(346 / 725)$ & Ns & $<0.05$ & $<0.05$ \\
\hline \multirow{2}{*}{\multicolumn{7}{|c|}{$\triangle A \cup C 0-36\left(h^{*} \mu g / l\right)$}} \\
\hline & & & & & & \\
\hline All & $79(-14 / 178)$ & $72(-7 / 211)$ & $136(43 / 246)$ & Ns & $<0.05$ & $<0.05$ \\
\hline Males & $126^{\dagger}(86 / 178)$ & $115^{\star}(50 / 211)$ & $167(134 / 246)$ & Ns & $<0.05$ & $<0.05$ \\
\hline Females & $26^{\dagger}(-14 / 84)$ & $20^{*}(-7 / 75)$ & $104(43 / 185)$ & Ns & $<0.03$ & $<0.02$ \\
\hline \multirow{2}{*}{\multicolumn{7}{|c|}{$\begin{array}{l}\text { IGFBP-3 } \\
\Delta \text { AUC } 0-36\left(h^{*} \mu \mathrm{g} / \mathrm{l}\right)\end{array}$}} \\
\hline & & & & & & \\
\hline All & $121.6(-116 / 580)$ & $164.2(-84 / 452)$ & $285.4(-122 / 664)$ & Ns & Ns & Ns \\
\hline Males & $172.5^{*}(-102 / 580)$ & $212.2^{\star}(-55 / 452)$ & $271.7(-60 / 664)$ & Ns & Ns & Ns \\
\hline Females & $82.5^{\star}(-116 / 390)$ & $108.5^{\star}(-84 / 275)$ & $302.2(-122 / 716)$ & Ns & Ns & Ns \\
\hline
\end{tabular}

${ }^{\star} P<0.05,{ }^{\dagger} P<0.01$ for difference between males and females calculated by the $U$-Mann-Whitney test. Wilcoxon test was used for between-group comparison. 

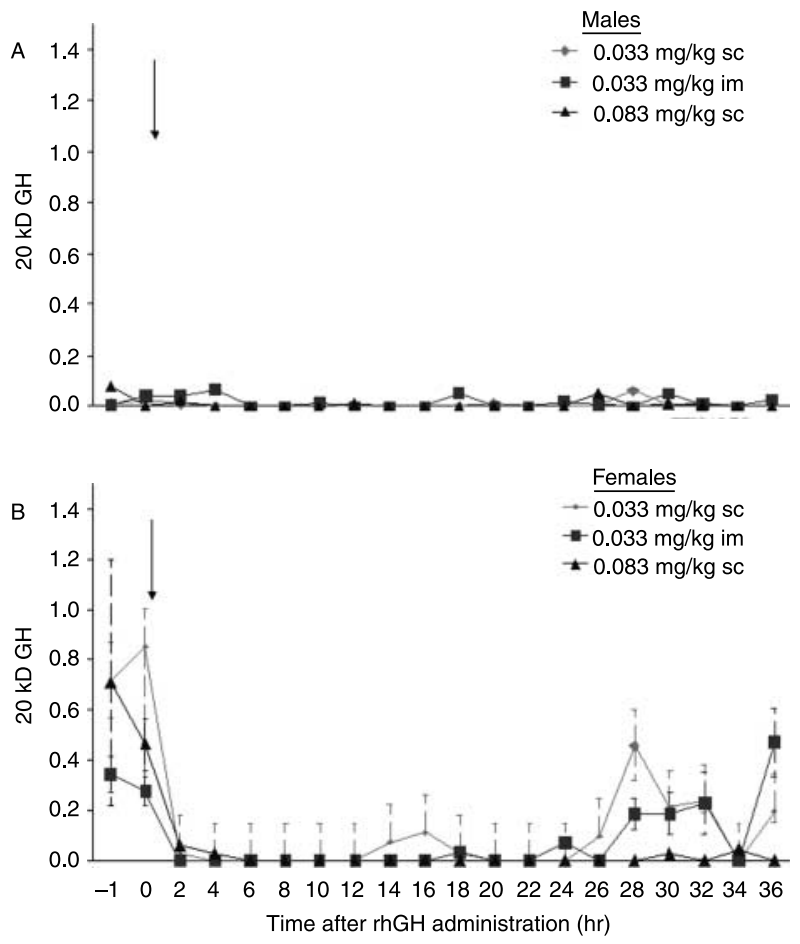

Figure 2 Serum concentration of $20 \mathrm{kDa} \mathrm{GH}$ after administration of rhGH at three different dosages; (A) males, (B) females. Values are median with the interquartile range (Q1-Q3).

Although one could have expected a higher $t_{1 / 2 \mathrm{z}}$ after s.c. administration in women, due to the higher s.c. fat (26), $t_{1 / 2 \mathrm{z}}$ was not affected by gender, perhaps because the women in the study were trained and lean.

The increase in IGF-I was positively correlated to baseline concentration, and was not affected by route of administration. Compared to IGFBP-3, the increase in serum IGF-I was faster and more pronounced, consistent with previous publications indicating that the ratio of IGF-I/IGFBP-3 increases immediately after rhGH injection (27). The increase in IGFBP-3 was delayed, not clearly dose dependent and did not return to baseline during the observation period, confirming that IGF-I is a more sensitive marker of GH action in trained adults than IGFBP-3.

The increase in IGF-I, but not the increase in IGFBP3 , shows a marked sexual dimorphism. Integrated IGF-I release after rhGH injection was significantly higher in males than females, whereas $T_{\max }$ and $C_{\max }$ did not differ between sexes. IGF-I and IGFBP 3 response is higher in males at low dose. However, it might be the case that the high dose of rhGH being a stronger stimulus also evokes a higher response in females. The difference between sexes is of course most likely due to the influence of estrogens, as all females were on oral contraceptives. No clear difference was seen in IGF-I response but the study was not specifically designed to investigate the impact of estrogens. It has been proposed that use of oral estrogens interferes with hepatic IGF-I production, but women not using estrogen supplementation also exhibit a lower IGF-I response than males (1). Studies in animals indicate that complex mechanisms, including modification of hepatic GH receptor expression, lead to the sexual dimorphism in the somatotropic axis (28). In contrast to serum GH concentrations, IGF-I and IGFBP-3 concentrations did not return to pre-treatment levels within the observation period, supporting the idea of use of these markers to detect doping with rhGH $(13,27,29)$.

The existing studies on the relationship between $22 \mathrm{kDa}$ and $20 \mathrm{kDa}$ isoforms suggest that the secretion is a part of constant percentage of total GH. Therefore, the lower $20 \mathrm{kDa}$ level and the long-term suppression in males seem to be a consequence of the lower total GH concentration. The $20 \mathrm{kDa} \mathrm{GH}$ isoform was also suppressed in females after administration of rhGH, consistent with a negative feedback of exogenous rhGH on pituitary GH secretion; the duration of suppression was dose dependent and re-occurrence of $20 \mathrm{kDa}$ in the circulation was seen 26-28 h after low-dose rhGH and $34 \mathrm{~h}$ after high dose rhGH. The prolonged changes provide further evidence that the $\mathrm{GH}$ isoform pattern can be used to detect the administration of rhGH in females. With the assay method used in this study, $20 \mathrm{kDa}$ GH levels in males were almost undetectable, making it impossible to demonstrate further suppression. Thus, more sensitive assays to quantify the amount of $20 \mathrm{kDa}$ GH are necessary.

In summary, our data show that in healthy trained adults, responsiveness to $\mathrm{rhGH}$ administration is regulated by a variety of factors. Pharmacokinetic parameters are mainly influenced by the route of administration, with higher $\mathrm{GH} C_{\max }$ and AUC after i.m. injection, while pharmacodynamic parameters are mainly determined by gender. These differences need to be considered when decisions are made regarding therapeutic dosing with rhGH. Changes in the molecular isoforms in circulation after injection of rhGH show that in females, measurement of $20 \mathrm{kDa} \mathrm{GH}$ could be a useful parameter to detect rhGH doping in athletes.

\section{Acknowledgements}

We thank all subjects for their full co-operation. Furthermore, we are grateful to the nurses and accompanying persons of the Endocrine Research Unit of the Hospital for Children and Adolescents, University of Leipzig, Germany. Additionally, we thank Dr Götz Gelbrich (Center of Coordination of Clinical Studies, University of Leipzig, Germany) for his support in data management. This study was supported by the National Institute of Sports Research (BISp), Bonn, Germany and by Eli Lilly Company, Bad Homburg, Germany. 


\section{References}

1 Burman P, Johansson AG, Siegbahn A, Vessby B \& Karlsson FA. Growth hormone (GH)-deficient men are more responsive to $\mathrm{GH}$ replacement than women. Journal of Clinical Endocrinology and Metabolism 199782 550-555.

2 Hoffman AR, Kuntze JE, Baptista J, Baum HB, Baumann GP, Biller BM, Clark RV, Cook D, Inzucchi SE, Kleinberg D, Klibanski A, Phillips LS, Ridgway EC, Robbins RJ, Schlechte J, Sharma M, Thorner MO \& Vance ML. Growth hormone (GH) replacement therapy in adult-onset GH deficiency: effects on body composition in men and women in a double-blind, randomized, placebocontrolled trial. Journal of Clinical Endocrinology and Metabolism 200489 2048-2056.

3 Attanasio AF, Bates PC, Ho KK, Webb SM, Ross RJ, Strasburger CJ, Bouillon R, Crowe B, Selander K, Valle D, Lamberts SW \& Hypoptituitary Control and Complications Study International Advisory Board . Human growth hormone replacement in adult hypopituitary patients: long-term effects on body composition and lipid status - 3-year results from the HypoCCS database. Journal of Clinical Endocrinology and Metabolism 200287 1600-1606.

4 Ho KK \& Weissberger AJ. Impact of short-term estrogen administration on growth hormone secretion and action: distinct route-dependent effects on connective and bone tissue metabolism. Journal of Bone and Mineral Research 19927 821-827.

5 Cook DM. Growth hormone and estrogen: a clinician's approach. Journal of Pediatric Endocrinology and Metabolism 200217 (Suppl 4) 1273-1276.

6 Langendonk JG, Meinders AE, Burggraaf J, Frolich M, Roelen CA, Schoemaker RC, Cohen AF \& Pijl H. Influence of obesity and body fat distribution on growth hormone kinetics in humans. American Journal of Physiology 1999277 E824-E829.

7 Hansen TK, Gravjolt CH, Orskov H, Rasmussen MH, Christiansen JS \& Jorgensen JO. Dose dependency of the pharmacokinetics and acute lipolytic action of growth hormone. Journal of Clinical Endocrinology and Metabolism 200287 4691-4698.

8 Jorgensen JO, Moller J, Moller N, Lauritzen T \& Christiansen JS. Pharmacological aspects of growth hormone replacement therapy: route, frequency and timing of administration. Hormone Research 19903 (Suppl 4) 77-82.

9 Russo L \& Moore WV. A comparison of subcutaneous and intramuscularly administration of human growth hormone in the therapy of growth hormone deficiency. Journal of Clinical Endocrinology and Metabolism 198255 1003-1006.

10 Kearns GL, Kemp SF \& Frindik JP. Single and multiple dose pharmacokinetics of methionyl growth hormone in children with idiopathic growth hormone deficiency. Journal of Clinical Endocrinology and Metabolism 199172 1148-1156.

11 Bidlingmaier M, Kim J, Savoy C, Kim MJ, Ebrecht N, de la Motte S \& Strasburger CJ. Comparative pharmacokinetics and pharmacodynamics of a new sustained-release growth hormone (GH), LBO3002, versus daily GH in adults with GH deficiency. Journal of Clinical Endocrinology and Metabolism 200691 2926-2930.

$12 \mathrm{Wu}$ Z, Bidlingmaier M, Dall R \& Strasburger CJ. Detection of doping with human growth hormone. Lancet 1999353895.

13 Bidlingmaier M, Wu Z \& Strasburger CJ. Doping with growth hormone. Journal of Pediatric Endocrinology and Metabolism 2001 14 (Suppl 4) 1077-1083.

14 Boguszewski CL, Hynsjo L, Johannsson G, Bengtsson BA \& Carlsson LM. 22-kDa growth hormone exclusion assay: a new approach to measurement of non-22-kDa growth hormone isoforms in human blood. European Journal of Endocrinology $1996135573-582$.

15 Wallace JD, Cuneo RC, Bidlingmaier M, Lundberg PA, Carlson L, Boguszewski CL, Hay J, Borooujerdi M, Cittadini A, Dall R, Rosen T \& Strasburger CJ. Changes in non-22-kilodalton $(\mathrm{kDa})$ isoforms of growth hormone $(\mathrm{GH})$ after administration of 22-kDa recombinant human $\mathrm{GH}$ in trained adult males. Journal of Clinical Endocrinology and Metabolism 200186 1731-1737.
16 Blum WF, Ranke MB, Kietzmann K, Gauggel E, Zeisel HJ \& Bierich JR. A specific radioimmunoassay for the growth hormone (GH)-dependent somatomedin-binding protein: its use for diagnosis of GH deficiency. Journal of Clinical Endocrinology and Metabolism $1990 \mathbf{7 0} 1292-1298$.

17 Straume M, Veldhuis JD \& Johnson ML. Model-independent quantification of measurement error: empirical estimation of discrete variance function profiles based on standard curves. Methods in Enzymology 1994240 121-150.

18 Jahreis G, Kauf E, Frohner G \& Schmidt HE. Influence of intensive exercise on insulin-like growth factor 1 , thyroid and steroid hormones in female gymnasts. Growth Regulation 1991 1 95-99.

19 Tigranian RA, Kalita NF \& Davydova NA. Observations on the Soviet/Canadian transpolar ski trek: status of selected hormones and biologically active compounds. Medicine and Science in Sports and Exercise 199233 106-138.

20 Ehrnborg C, Bengtson C \& Rosen T. Growth hormone abuse. Baillieres Best Practice and Research. Clinical Endocrinology and Metabolism 200014 71-77.

21 Cuneo RC, Judd S, Wallace JD, Perry-Keene D, Burger H, Lim-Tio S, Strauss B, Stockigt J, Topliss D, Alford F, Hew L, Bode H, Conway A, Handelsman D, Dunn S, Boyages S, Cheung NW \& Hurley D. The Australian Multicenter Trial of Growth Hormone (GH) treatment in GH-deficient adults. Journal of Clinical Endocrinology and Metabolism $1998 \mathbf{8 3} 107-116$.

22 Growth Hormone Research Society. Invited report of a workshop: consensus guidelines for the diagnosis and treatment of adults with growth hormone deficiency: summary statement of the Growth Hormone Research Society Workshop on Adult Growth Hormone Deficiency. Journal of Clinical Endocrinology and Metabolism $1998 \mathbf{8 3} 379$-381.

23 Root AW, Kemp SF, Rundle AC, Dana K \& Attie KM. Effect of longterm recombinant growth hormone therapy in children and adults - the National Cooperative Growth Study, USA, 19851994. Journal of Pediatric Endocrinology and Metabolism: 199811 403-412.

24 Hansen TK, Møller J, Thomsen K, Frandsen K, Dall R, Jørgensen JO \& Christiansen JS. Effects of growth hormone on renal tubular handling of sodium in healthy humans. American Journal of Physiology. Endocrinology and Metabolism 2001281 E1326-E1332.

25 Laursen T. Clinical pharmacological aspects of growth hormone administration. Growth Hormone and IGF Research 200414 16-44.

26 Vahl N, Moller N, Lauritzen T, Christiansen JS \& Jorgensen JO. Metabolic effects and pharmacokinetics of a growth hormone pulse in healthy adults: relation to age, sex, and body composition. Journal of Clinical Endocrinology and Metabolism 199782 3612-3618.

27 Wallace JD, Ross C, Baxter R, Orskov O, Keay N, Dall R, Rosen T, Jorgensen JO, Cittadini A, Longobardi S, Sacca L, Christiansen JS, Bengtsson B \& Sönksen PH. Responses of the growth hormone (GH) and insulin-like growth factor axis to exercise, GH administration and $\mathrm{GH}$ withdrawal in trained adult males: a potential test for GH abuse in sport. Journal of Clinical Endocrinology and Metabolism 199984 3591-3598.

28 Giustina A \& Veldhius JD. Pathophysiology of the neuroregulation of $\mathrm{GH}$ secretion in experimental animals and the human. Endocrine Reviews $199819717-797$.

29 Longobardi S, Keay N, Ehrnborg C, Cittadini A, Rosén A, Dall A, Boroujerdi MA, Bassett EE, Healy ME, Pentecost C, Wallace JD, Powrie J, Jørgensen JO \& Sacca JA. Growth hormone (GH) effects on bone and collagen turnover in healthy adults and its potential as a marker of GH abuse in sports: A double blind, placebo-controlled study. The GH-2000 study Group. Journal of Clinical Endocrinology and Metabolism 200085 1505-1512.

Received 27 January 2007

Accepted 14 March 2007 